\title{
Hypothalamic Adhesions: Asymptomatic, Incidental, or Not?
}

T he term "hypothalamic adhesion" was first described in 2008 as a common associated finding (48\%) in Chiari II malformation by the neuroradiology group at the Hospital for Sick Children in Toronto. ${ }^{1}$ It has been subsequently presented outside the context of Chiari II in a number of radiologic meetings by us and other groups since 2010 and has been variously referred to as hypothalamic adhesions, hypothalamic fusion bands, interhypothalamic adhesions, intrahypothalamic adhesions, transhypothalamic connections, and even asymptomatic hypothalamic hamartomas. We do not prefer the term "interhypothalamic" because anatomically, there is only 1 hypothalamus that extends to both sides via the tuber cinereum and floor of the third ventricle. Routine use of high-resolution imaging facilitates the detection of this imaging finding, and it is expected that more reports of this finding and its potential association will follow.

In 2014, the presence of this finding was reported in the American Journal of Neuroradiology (AJNR) to be highly associated with other malformations and abnormalities in most instances, in a small case series of 13 patients. ${ }^{2}$ The authors proposed that it may be a form fruste of holoprosencephaly, given the prevalence of midline abnormalities. Ahmed et $\mathrm{al}^{3}$ recently reported in the AJNR that most patients with this finding are asymptomatic and that these are often incidental findings. So what is the practitioner to do with these seemingly conflicting results? How would the neuroradiologist explain the significance of this finding to referring physicians and patients, given that it is so sparsely reported in the literature? Every time we describe this finding in our clinical radiology reports, we receive these inevitable enquiries from our colleagues. These questions could only be explained with further

http://dx.doi.org/10.3174/ajnr.A4743 cumulative experience in the field, a larger number of patients, and perhaps genomic testing.

In our experience with 3 dozen of these cases in the past 6 years, most were not associated with clinical symptomatology referable to the hypothalamic-pituitary axis and most did not have other anatomic abnormalities. Even when some patients underwent endocrine work-up, no abnormality was found. Nevertheless, we had 1 patient with central precocious puberty and 4 presenting with seizures, though the seizure characteristics were not typical of those with hypothalamic hamartomas. Even though 2 had callosal abnormalities and 3 had nodular heterotopias in our cohort, most have not been associated with discernible midline or nonmidline abnormalities on MR imaging, in our experience. While it is certainly prudent to carefully look for subtle midline and other anatomic abnormalities, we agree with the main tenet of the article by Ahmed et $\mathrm{al}^{3}$ that neuroradiologists and other care team members perhaps should not be unnecessarily alarmed because these findings can be incidental in many patients.

\section{REFERENCES}

1. Miller E, Widjaja E, Blaser S, et al. The old and the new: supratentorial MR findings in Chiari II malformation. Childs Nerv Syst 2008;24: 563-75 CrossRef Medline

2. Whitehead MT, Vezina G. Interhypothalamic adhesion: a series of $\mathbf{1 3}$ cases. AJNR Am J Neuroradiol 2014;35:2002-06 CrossRef Medline

3. Ahmed FN, Stence NV, Mirsky DM. Asymptomatic interhypothalamic adhesions in children. AJNR Am J Neuroradiol 2015 Dec 3. [Epub ahead of print] CrossRef Medline

(D)A. Vossough (D) S.A. Nabavizadeh University of Pennsylvania Children's Hospital of Philadelphia Philadelphia, Pennsylvania 